\title{
Flora bacteriana conjuntival após uso tópico de ciprofloxacino e gatifloxacino em cirurgia de catarata
}

\author{
Conjunctival bacterial flora after topical use of ciprofloxacin and gatifloxacin \\ in cataract surgery
}

\author{
Tiago Eugênio Faria e Arantes ${ }^{1}$ \\ Célia Maria Machado Barbosa de Castro ${ }^{2}$ \\ Ronald Fonseca Cavalcanti ${ }^{3}$ \\ Maiara Santos Severo ${ }^{4}$ \\ Maria de Fátima Alves Diniz ${ }^{5}$ \\ Ricardo Walber de Deus Urtig'a ${ }^{6}$
}

Trabalho desenvolvido na Fundação Altino Ventura FAV-Recife (PE) - Brasil.

${ }^{1}$ Pós-graduando nível Doutorado do Setor de Uveítes e AIDS do Departamento de Oftalmologia da Universidade Federal de São Paulo - UNIFESP - São Paulo (SP) - Brasil.

${ }^{2}$ Professora Adjunta do Departamento de Medicina Tropical da Universidade Federal de Pernambuco - UFPE - Recife (PE) - Brasil.

${ }^{3}$ Chefe do Departamento de Córnea e Doenças Externas da Fundação Altino Ventura - FAV - Recife (PE) - Brasil.

${ }^{4}$ Estagiária de Iniciação Científica do Laboratório de Imunopatologia Keizo-Asami da UFPE - Recife (PE) Brasil.

${ }^{5}$ Biomédica do Laboratório de Imunopatologia KeizoAsami da UFPE - Recife (PE) - Brasil.

${ }^{6}$ Médico oftalmologista pelo Curso de Residência da FAV - Recife (PE) - Brasil.

Endereço para correspondência: Tiago Eugênio Faria e Arantes. Rua Pedro de Toledo, 544 - Apto. 711 São Paulo (SP) CEP 04039-001

E-mail: t_arantes@yahoo.com

Recebido para publicação em 19.05.2007

Última versão recebida em 02.10 .2007

Aprovação em 25.10.2007

Nota Editorial: Depois de concluída a análise do artigo sob sigilo editorial e com a anuência da Dra. Denise de Vuono Chinzon sobre a divulgação de seu nome como revisora, agradecemos sua participação neste processo.

\section{RESUMO}

Objetivo: Avaliar alterações da flora conjuntival após uso dos colírios de ciprofloxacino gatifloxacino $0,3 \%$ na profilaxia dos pacientes submetidos à facectomia. Métodos: Quarenta pacientes submetidos a facectomia foram alocados em dois grupos, conforme o colírio antibiótico utilizado: Grupo A: ciprofloxacino 0,3\% e Grupo B: gatifloxacino 0,3\%. Os pacientes usaram os colírios 1 hora antes da cirurgia e nos primeiros 14 dias pós-operatórios. Foi coletado material da conjuntiva em cinco momentos: 1 hora antes da cirurgia, sem medicações tópicas ( $\left.\mathrm{t}_{0}\right)$; imediatamente antes da aplicação de iodopovidona (PVPI) $\left(\mathrm{t}_{1}\right)$, antes do início da cirurgia, após iodopovidona $\left(\mathrm{t}_{2}\right), 14$ dias após a cirurgia $\left(\mathrm{t}_{3}\right)$ e 28 dias após a cirurgia $\left(\mathrm{t}_{4}\right)$. Resultados: $\mathrm{O}$ uso de antibióticos no pré-operatório diminuiu a positividade das culturas anteriores ao uso do iodopovidona em ambos os grupos; no Grupo A esta redução não alcançou significância estatística (Grupo A - p=0,07 e Grupo $\mathrm{B}$ - $\mathrm{p}=0,04)$. A positividade das culturas foi reduzida nos dois grupos após aplicação de iodopovidona e 14 dias após a cirurgia $(\mathrm{p}<0,05)$. Em $\mathrm{t}_{4}$ a frequiência do Staphylococcus coagulase-negativo foi menor no grupo A quando comparado ao grupo B $(\mathrm{p}<0,05)$ e a sensibilidade ao ciprofloxacino em relação a t foi menor em todos grupos. Conclusão: O colírio de gatifloxacino aplicado 1 hora antes da cirurgia reduziu significantemente a positividade das culturas. Ambos antibióticos promoveram redução da flora quando administrados no pós-operatório.

Descritores: Conjuntiva/microbiologia; Antibioticoprofilaxia; Ciprofloxacino/uso terapêutico; Povidone-iodine; Resistência microbiana a drogas; Extração de catarata; Soluções oftálmicas; Endoftalmite

\section{INTRODUÇÃO}

A endoftalmite pós-operatória, embora rara, é uma das mais temidas e devastadoras complicações da cirurgia intra-ocular, com uma incidência de aproximadamente $0,082 \%$ em cirurgias de catarata ${ }^{(1)}$. Na maioria dos casos, os organismos responsáveis pela infecção se originam das pálpebras e conjuntiva do próprio paciente ${ }^{(2-4)}$. As bactérias constituem o grupo mais comum de agentes causadores de endoftalmite, sendo os microorganismos Gram-positivos responsáveis por $60 \%$ a $80 \%$ das infecções agudas ${ }^{(4)}$. Existem evidências da penetração destes microorganismos durante a cirurgia de catarata, embora este fato não signifique necessariamente uma infecção, sugerindo que a câmara anterior é capaz de eliminar pequenos inóculos de bactérias sem que se desenvolva endoftalmite ${ }^{(5-6)}$.

Desta forma, acredita-se que se reduzindo o número e o crescimento de 
bactérias na superfície e anexos oculares previamente à cirurgia, o risco de infecção pós-operatória seria diminuído. Sendo assim, várias medidas profiláticas têm sido usadas neste sentido, entre elas o uso de iodo-povidona (PVPI) no pré-operatório, uso de antibióticos no peri-operatório e isolamento de cílios ${ }^{(2)}$.

Em extensa revisão da literatura, o uso de PVPI no preparo pré-operatório das cirurgias intra-oculares foi a única medida considerada comprovadamente capaz de diminuir a incidência de endoftalmite pós-facectomia ${ }^{(2)}$. Entretanto, é descrito que a aplicação de antibióticos tópicos no pré-operatório, combinados ao uso do PVPI, é capaz de reduzir ainda mais a colonização bacteriana na conjuntiva ${ }^{(7)}$.

Embora ainda não tenha sido determinada a dose, freqüência, tempo e tipo de antibiótico tópico mais adequado para a profilaxia perioperatória, é aceito que estes são eficientes em reduzir a flora bacteriana da conjuntiva ${ }^{(7-12)}$. A escolha do antibiótico a ser utilizado será influenciada por fatores como espectro de cobertura bacteriana, rapidez na eliminação das bactérias na superfície conjuntival, duração da ação, biodisponibilidade, toxicidade, padrões de susceptibilidade e custo ${ }^{(9-11)}$. Entre os antibióticos mais utilizados atualmente estão as fluoroquinolonas, principalmente devido ao seu amplo espectro de cobertura bacteriana e biodisponibilidade ${ }^{(9-10,13-15)}$.

O objetivo deste estudo foi avaliar as alterações da flora conjuntival após o uso dos colírios de ciprofloxacino ou gatifloxacino a $0,3 \%$ na profilaxia dos pacientes submetidos à cirurgia de catarata, além do padrão de susceptibilidade e recuperação desta flora com o seu uso.

\section{MÉTODOS}

Foi realizado estudo prospectivo de 40 pacientes (40 olhos) submetidos a cirurgia de catarata pela técnica de facoemulsificação no período de março a setembro de 2005 na Fundação Altino Ventura, Recife - Pernambuco.

Todos os pacientes foram submetidos previamente a exame oftalmológico completo. Foram excluídos os pacientes com sinais de blefarite e meibomite, pacientes em uso de medicação tópica ocular anteriormente à cirurgia e pacientes submetidos a cirurgias oftalmológicas prévias.

Os pacientes foram alocados em dois grupos, conforme o uso de antibiótico tópico: Grupo A: colírio de ciprofloxacino a 0,3\% e Grupo B: colírio de gatifloxacino a 0,3\%. Ambos os grupos tiveram o colírio antibiótico instilado no pré-operatório na forma de uma gota a cada cinco minutos, no total de três aplicações, começando uma hora antes da cirurgia. Os dois grupos utilizaram colírios antibióticos de 6/6 horas nos primeiros 14 dias de pós-operatório e colírio de acetato de prednisolona a $1 \%$ durante 28 dias após a cirurgia, iniciado de $3 / 3$ horas e com redução gradativa de uma gota a cada cinco dias. Os pacientes dos dois grupos receberam duas gotas de iodopovidona a $5 \%$ (PVPI) no fundo de saco inferior anteriormente à cirurgia, assim como o preparo anti-séptico da área periorbital, cílios e pálpebras com PVPI. A cirurgia foi iniciada cinco minutos após a aplicação de PVPI. Antibióticos intracamerulares ou na solução de irrigação não foram utilizados durante a cirurgia.

Foi coletado material da conjuntiva em cinco momentos: uma hora antes da cirurgia, sem aplicação de medicações tópicas $\left(\mathrm{t}_{0}\right)$; imediatamente antes da aplicação de PVPI tópico $\left(\mathrm{t}_{1}\right)$; imediatamente antes do início da cirurgia, cinco minutos após a aplicação de PVPI $\left(\mathrm{t}_{2}\right) ; 14$ dias após a cirurgia $\left(\mathrm{t}_{3}\right)$ e 28 dias após a cirurgia $\left(\mathrm{t}_{4}\right)$.

O material da conjuntiva foi coletado através de swab no fundo de saco conjuntival inferior, sem tocar pálpebras ou cílios, e colocado em meio de transporte Stuart. A partir do material coletado foram realizadas bacterioscopias e semeio para culturas com isolamento, identificação das bactérias e confecção de antibiogramas. O processo de investigação microbiológica seguiu as seguintes etapas: (1) Bacterioscopia: o swab uma vez coletado foi rolado sobre uma lâmina de vidro para microscopia óptica sendo em seguida, fixada rapidamente em chama e corada pelo método de coloração do Gram; (2) Cultura: foram utilizadas duas placas (ágar-sangue e ágarLevine) para o cultivo de bactérias e uma placa (ágar Sabouraud) para o cultivo de fungos. O material coletado pelo swab foi rolado num canto de uma placa de Petri com meio de cultura sólido e com auxílio de uma alça de platina, o material foi espalhado no sentido do maior diâmetro da placa, em estrias, cobrindo toda superfície do meio. Este procedimento permitiu o crescimento isolado das colônias. Posteriormente, as placas foram incubadas à temperatura de $36^{\circ} \mathrm{C} \pm 1^{\circ} \mathrm{C}$ por $24 \mathrm{a} 48 \mathrm{~h}$ e em caso de obtenção de cultura positiva, foi realizado antibiograma; (3) Antibiograma: os microorganismos isolados foram submetidos ao teste de sensibilidade de difusão em discos. A leitura foi feita medindo-se o diâmetro do halo de inibição ao redor do disco de acordo com critérios do Clinical and Laboratorial Standards Institute - CLSI.

A inclusão dos pacientes nos grupos foi de forma alternada até completar o número da amostra.

Foi utilizado como banco de dados o programa Epi-Info v3.3. Para análise estatística utilizou-se o teste exato de McNemar para análise das diferenças entre os momentos de coleta e o teste exato de Fisher para avaliar associações entre os grupos. Aceitou-se $\mathrm{p}<0,05$ para rejeição da hipótese de nulidade.

A pesquisa foi iniciada após aprovação pelo Comitê de Ética da Fundação Altino Ventura. Foi obtido consentimento livre e esclarecido de cada paciente incluído no estudo.

\section{RESULTADOS}

Entre os pacientes estudados, 25 eram do sexo feminino $(62,5 \%)$ e 15 do masculino $(37,5 \%)$. A média de idade foi de $62,9 \pm 11,4$ anos.

O resultado das culturas dos grupos estudados em cada momento de coleta está expresso na tabela 1 e o percentual de culturas positivas está apresentado na figura 1. Houve dimi- 


\begin{tabular}{|c|c|c|c|c|c|c|c|c|c|c|}
\hline \multirow{2}{*}{$\begin{array}{l}\text { Grupo A }(n=20) \\
\text { Culturas }\end{array}$} & \multicolumn{2}{|c|}{$t_{0}$} & \multicolumn{2}{|c|}{$t_{1}$} & \multicolumn{2}{|c|}{$t_{2}$} & \multicolumn{2}{|c|}{$t_{3}$} & \multicolumn{2}{|c|}{$t_{4}$} \\
\hline & + & - & + & - & + & - & + & - & + & - \\
\hline $\mathrm{n}$ & 16 & 4 & 10 & 10 & 5 & 15 & 5 & 15 & 9 & 11 \\
\hline$\%$ & 80,0 & 20,0 & 50,0 & 50,0 & 25,0 & 75,0 & 25,0 & 75,0 & 45,0 & 55,0 \\
\hline $\mathrm{p}^{*}$ & & & \multicolumn{2}{|r|}{0,070} & & 0,001 & \multicolumn{2}{|r|}{0,001} & \multicolumn{2}{|c|}{0,065} \\
\hline Grupo B $(n=20)$ & \multicolumn{2}{|c|}{$t_{0}$} & \multicolumn{2}{|c|}{$t_{1}$} & \multicolumn{2}{|c|}{$t_{2}$} & \multicolumn{2}{|c|}{$t_{3}$} & \multicolumn{2}{|c|}{$t_{4}$} \\
\hline Culturas & + & - & + & - & + & - & + & - & + & - \\
\hline $\mathrm{n}$ & 15 & 5 & 8 & 12 & 4 & 16 & 7 & 13 & 6 & 14 \\
\hline$\%$ & 75,0 & 25,0 & 40,0 & 60,0 & 20,0 & 80,0 & 35,0 & 65,0 & 30,0 & 70,0 \\
\hline $\mathrm{p}^{*}$ & & & & 0,039 & & 0,001 & & 0,038 & & 0,022 \\
\hline
\end{tabular}

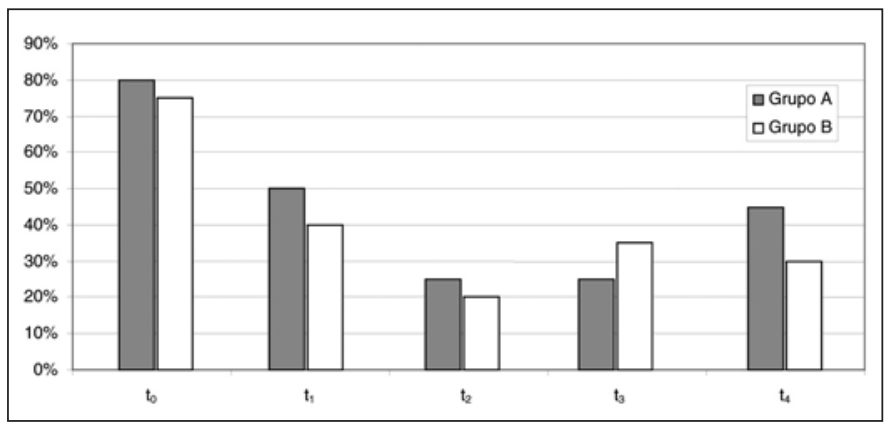

Figura 1 - Percentual de culturas conjuntivais positivas

nuição na positividade das culturas anteriores à aplicação do PVPI $\left(t_{1}\right)$ em relação a $t_{0}$ em ambos os grupos, sendo esta estatisticamente significante no Grupo B (Grupo A: $p=0,07$, Grupo $B: p=0,04)$. Houve redução significante do número de culturas positivas nos dois grupos após a aplicação de PVPI $\left(\mathrm{t}_{2}\right)$ e 14 dias após a cirurgia $\left(\mathrm{t}_{3}\right)(\mathrm{p}<0,05)$. O número de culturas positivas 28 dias depois da cirurgia, após 14 dias da interrupção do uso de antibióticos tópicos $\left(\mathrm{t}_{4}\right)$, foi inferior à positividade nas culturas iniciais $\left(\mathrm{t}_{0}\right)$ em ambos os grupos, não alcançando significância estatística no Grupo A ( $\mathrm{p}=0,07$ e p $=0,02$, respectivamente). Não houve diferença estatisticamente significante no número de culturas positivas entre os dois grupos quando comparados em momentos de coleta semelhantes.

$\mathrm{Na}$ tabela 2 estão expressas as frequiências das bactérias isoladas nos diferentes grupos em cada momento de coleta. Ao avaliar-se as modificações na diversidade bacteriana da flora conjuntival, observou-se em $\mathrm{t}_{4}$ diminuição significante na frequiência de colônias de Staphylococcus coagulase negativo no grupo que usou ciprofloxacino (Grupo A: 38,5\%) comparado ao que usou gatifloxacino (Grupo B: 100,0\%) (p<0,05), tal diminuição não foi estatisticamente significante entre os grupos nos outros momentos de coleta.

Encontrou-se redução na sensibilidade ao ciprofloxacino em $t_{4}$, em comparação a $t_{0}$, nos dois grupos, não havendo diferença estatística entre os grupos. O número de colônias resistentes ao gatifloxacino foi menor que ao ciprofloxacino em todos os grupos, porém esta diferença não foi significante (Tabela 3).

\section{DISCUSS ÃO}

A aplicação de PVPI no fundo de saco conjuntival inferior no pré-operatório é um procedimento seguro, rápido e eficiente, sendo considerada a técnica profilática de maior impacto na redução da incidência de endoftalmite pós-operatória ${ }^{(2)}$. $\mathrm{Na}$ literatura é descrito que a combinação de PVPI a antibióticos tópicos instilados no pré-operatório resulta em maior diminuição da flora conjuntival do que a encontrada com o uso isolado destas substâncias ${ }^{(7)}$. Todavia, existem poucos dados em relação à maneira de uso destes antibióticos na profilaxia préoperatória e quais os antibióticos mais adequados ${ }^{(7-11)}$.

Pesquisas mostram que mais de $80 \%$ dos oftalmologistas prescrevem antibióticos tópicos no pré-operatório, existindo várias maneiras descritas para sua utilização, desde utilização dias antes da cirurgia até nas horas precedendo o procedimento operatório ${ }^{(15)}$. O antibiótico usado no pré-operatório com a finalidade de diminuir a flora conjuntival deve ter entre suas características amplo-espectro de ação, alta potência bactericida, ação rápida, biodisponibilidade apropriada e baixa toxicidade. Sendo assim, a escolha freqüentemente recai sobre as fluoroquinolonas ${ }^{(9-10,13-15)}$.

A aplicação de ofloxacino tópico por três dias antes da cirurgia é mais eficiente na eliminação da flora bacteriana conjuntival que a sua aplicação uma hora antes da $\operatorname{cirurgia}^{(9)}$. Entretanto, o ciprofloxacino parece ter um efeito mais rápido na redução da flora que o ofloxacino, sendo descrito redução significante da flora bacteriana após 15 minutos de sua instilação ${ }^{(10)}$. Embora a antibioticoprofilaxia leve a uma redução da flora conjuntival, estudos recentes mostraram que o uso de fluoroquinolonas de quarta geração na profilaxia de cirurgias de catarata não levou a uma maior redução na incidência da endoftalmite pós-operatória ${ }^{(16-17)}$.

Neste estudo, foi observada uma redução significante do número de culturas positivas em $\mathrm{t}_{1}$ após o uso de gatifloxacino $(\mathrm{p}=0,04)$, a redução encontrada no grupo que usou ciprofloxacino no pré-operatório (Grupo A) não alcançou significância estatística $(\mathrm{p}=0,07)$, embora este achado possa estar relacionado ao número reduzido da amostra. Após a aplicação do PVPI $\left(\mathrm{t}_{2}\right)$ foram encontrados os menores números de culturas 


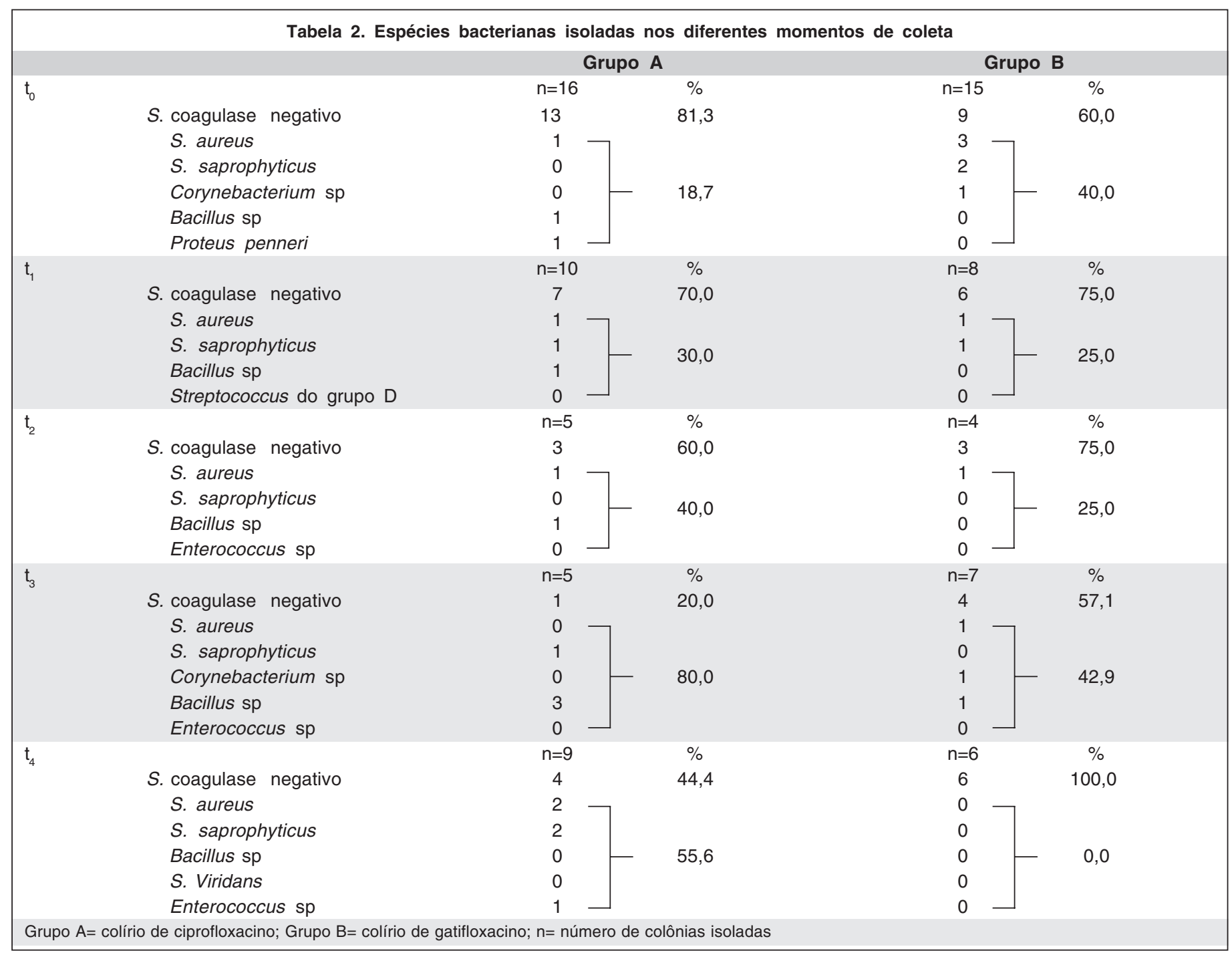

positivas, com redução significante em relação a $t_{0}$ em ambos os grupos, sem que houvesse diferença entre estes $(p>0,05)$.

O nível de redução da positividade das culturas com o uso pós-operatório de antibióticos no $14^{\circ}$ dia pós-operatório $\left(\mathrm{t}_{3}\right)$ foi significante para ambos os grupos $(\mathrm{p}<0,05)$ e não houve diferença estatística entre os grupos, sugerindo que ambos antibióticos são eficientes em reduzir a flora durante o seu uso no pós-operatório. Os pacientes que utilizaram gatifloxacino (Grupo B) permaneceram com esta redução mesmo 14 dias após a suspensão dos antibióticos $\left(\mathrm{t}_{4}\right)(\mathrm{p}=0,02)$. Porém, não houve diferença significante em comparação com o Grupo A neste mesmo momento.

A bactéria mais freqüentemente isolada foi o Staphylococcus coagulase negativo, coincidindo com o descrito na literatura $^{(11-12,18-20)}$. Após a recuperação da flora em $\mathrm{t}_{4}$ os pacientes que utilizaram ciprofloxacino apresentaram uma diminuição na freqüência desta bactéria, esta redução não foi encontrada com o uso de gatifloxacino $(\mathrm{p}=0,04)$. Este achado sugere que o uso do ciprofloxacino possa levar a uma maior modificação da colonização bacteriana da flora conjuntival.

Ao analisar-se o resultado dos antibiogramas, foi observado que as colônias bacterianas isoladas em $\mathrm{t}_{4}$ nos dois grupos foram menos susceptíveis ao ciprofloxacino que as isoladas nas culturas iniciais $\left(\mathrm{t}_{0}\right)$, sem que houvesse diferença estatística entre os grupos. As bactérias isoladas apresentaram níveis de susceptibilidade satisfatórios ao gatifloxacino (acima de 80\%) em todos os momentos nos dois grupos. Desta forma, parece haver uma tendência ao desenvolvimento de resistência ao ciprofloxacino após o uso de ambos os antibióticos, o mesmo não ocorreu em relação ao gatifloxacino, possivelmente isto se relaciona ao mecanismo de ação destes antibióticos e a seleção de mutantes resistentes ${ }^{(13-14)}$. Tem sido descrita uma diminuição da eficácia in vitro do ciprofloxacino contra os patógenos responsáveis pela maioria dos casos de endoftalmite pós-operatória $^{(21)}$ e nas bactérias encontradas na superfície ocular ${ }^{(11)}$.

Uma vez que a incidência de endoftalmite é muito baixa, um estudo adequado necessitaria de um grande número de pa- 


\begin{tabular}{|c|c|c|c|c|c|c|c|c|c|c|c|c|c|}
\hline & & & 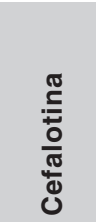 & 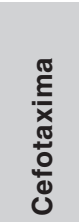 & $\begin{array}{l}\stackrel{0}{\frac{c}{0}} \\
\mathbb{2} \\
\frac{0}{0} \\
\frac{0}{0}\end{array}$ & 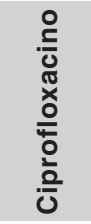 & 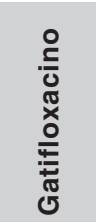 & $\begin{array}{l}\frac{\pi}{\frac{D}{0}} \\
\frac{0}{E} \\
\frac{10}{0} \\
\frac{0}{0}\end{array}$ & 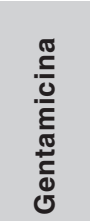 & 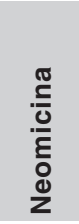 & 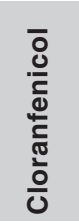 & 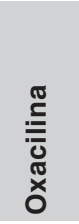 & 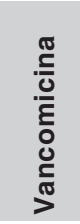 \\
\hline \multirow{4}{*}{ Grupo A } & $t_{0}$ & $S$ & 15 & 14 & 16 & 16 & 16 & 14 & 14 & 14 & 15 & 13 & 15 \\
\hline & $\mathrm{n}=16$ & $\%$ & 93,8 & 87,5 & 100,0 & 100,0 & 100,0 & 87,5 & 87,5 & 87,5 & 93,8 & 81,3 & 93,8 \\
\hline & $\mathrm{t}_{4}$ & $S$ & 12 & 11 & 11 & 7 & 11 & 7 & 9 & 8 & 12 & 10 & 13 \\
\hline & $n=13$ & $\%$ & 92,3 & 84,6 & 84,6 & 53,8 & 84,6 & 53,8 & 69,2 & 61,5 & 92,3 & 76,9 & 100,0 \\
\hline \multirow{4}{*}{ Grupo B } & $t_{0}$ & $S$ & 15 & 14 & 14 & 13 & 15 & 10 & 14 & 13 & 12 & 13 & 14 \\
\hline & $n=15$ & $\%$ & 100,0 & 93,3 & 93,3 & 86,7 & 100,0 & 66,7 & 93,3 & 86,7 & 80,0 & 86,7 & 93,3 \\
\hline & $\mathrm{t}_{4}$ & $S$ & 6 & 5 & 6 & 3 & 6 & 5 & 6 & 5 & 5 & 4 & 6 \\
\hline & $\mathrm{n}=6$ & $\%$ & 100,0 & 83,3 & 100,0 & 50,0 & 100,0 & 83,3 & 100,0 & 83,3 & 83,3 & 66,7 & 100,0 \\
\hline
\end{tabular}

cientes para comprovar a eficácia de uma técnica profilática na redução da sua incidência. Sabendo-se que a conjuntiva e pálpebras são as fontes mais comuns das bactérias causadoras de endoftalmite, pode-se assumir que se reduzindo o número de bactérias presentes nas pálpebras e conjuntiva no momento da cirurgia diminui-se o risco de endoftalmite, embora isto não tenha sido ainda comprovado.

\section{CONCLUSÃO}

Ocorreu diminuição do número de culturas conjuntivais positivas com o uso de colírios de ciprofloxacino e gatifloxacino aplicados uma hora antes da cirurgia, sendo esta redução significante com o gatifloxacino. Após a aplicação do PVPI foram encontrados os menores números de culturas positivas e não houve diferença entre os grupos que utilizaram ciprofloxacino e gatifloxacino no pré-operatório. Ambos antibióticos produziram redução da flora conjuntival enquanto estavam sendo administrados no pós-operatório. As colônias bacterianas isoladas após recuperação da flora conjuntival $\left(\mathrm{t}_{4}\right)$ foram menos susceptíveis ao ciprofloxacino que as isoladas nas culturas iniciais $\left(\mathrm{t}_{0}\right)$ em ambos os grupos, sem que houvesse diferença estatística entre eles. Em $\mathrm{t}_{4}$ houve ainda alteração do padrão de colonização bacteriana com o uso de ciprofloxacino, com diminuição da freqüência do Staphylococcus coagulase negativo.

\section{ABSTRACT}

Purpose: To evaluate alterations of the conjunctival flora after the use of $0.3 \%$ ciprofloxacin and gatifloxacin in the prophylaxis of patients undergoing cataract surgery. Methods: 40 patients undergoing cataract surgery were distributed into two groups according to the use of antibiotic eye drops: Group A: $0.3 \%$ ciprofloxacin and Group B: $0.3 \%$ gatifloxacin. Both groups used antibiotic eye drops 1 hour before surgery and 14 days after surgery. Conjunctival material was collected at 5 time points: 1 hour before surgery, without any topical medication $\left(\mathrm{t}_{0}\right)$; immediately before the application of povidone-iodine (PVPI) $\left(\mathrm{t}_{1}\right)$, before the beginning of surgery, after povidone-iodine $\left(\mathrm{t}_{2}\right), 14$ days $\left(\mathrm{t}_{3}\right)$ and 28 days after surgery $\left(\mathrm{t}_{4}\right)$. Results: Preoperative antibiotics reduced the positivity of the cultures before the use of PVPI in both groups, although in Group A this reduction was not significant (Group A - $\mathrm{p}=0.07$ and Group B - $p=0.04)$. The number of positive cultures was reduced in all groups after the use of povidone-iodine and on the $14^{\text {th }}$ postoperative day $(\mathrm{p}<0.05)$. In $\mathrm{t}_{4}$ there was a reduction in the frequency of coagulase-negative Staphylococcus in Group A compared with Group B $(\mathrm{p}<0.05)$; the susceptibility to ciprofloxacin was also reduced in all groups, when compared with t $\mathrm{t}_{0}$. Conclusions: Gatifloxacin eye drops applied one hour before surgery significantly reduced the number of positive conjunctival cultures. Both antibiotics reduced the conjunctival flora when administered in the postoperative period.

Keywords: Conjunctiva/microbiology; Antibiotic prophylaxis; Ciprofloxacin/therapeutic use; Povidone-iodine; Drug resistance, microbial; Cataract extraction; Ophthalmic solutions; Endophthalmitis

\section{REFERÊNCIAS}

1. Aarberg TM Jr, Flynn HW Jr, Schiffman J, Newton J. Nosocomial acute onset postoperative endophthalmitis survey. A 10-year review of incidence and outcomes. Ophthalmology. 1998;105(6):1004-10.

2. Ciulla TA, Starr MB, Masket S. Bacterial endophthalmitis prophylaxis for cataract surgery: an evidence-based update. Ophthalmology. 2002;109(1):1324. Comment in: Ophthalmology. 2003;110(8):1667; author reply 1667-8; Ophthalmology. 2003;110(8):1668; author reply 1669.

3. Kanellopoulos AJ, Dreyer EB. Postoperative infection following current cataract extraction surgery. Int Ophthalmol Clin. 1996;36(3):97-107.

4. Speaker MG, Milch FA, Shah MK, Eisner W, Kreiswirth BN. Role of external bacterial flora in the pathogenesis of acute postoperative endophthalmitis. Ophthalmology. 1991;98(5):639-49; discussion 650. 
5. Dickey JB, Thompson KD, Jay WM. Anterior chamber aspirate cultures after uncomplicated cataract surgery. Am J Ophthalmol. 1991;112(3):278-82. Comment in: Am J Ophthalmol. 1992;113(2):221-2.

6. Samad A, Solomon LD, Miller MA, Mendelson J. Anterior chamber contamination after uncomplicated phacoemulsification and intraocular lens implantation. Am J Ophthalmol. 1995;120(2):143-50.

7. Isenberg S, Apt L, Yoshimori R, Khwarg S. Chemical preparation of the eye in ophthalmic surgery. IV. Comparison of povidone-iodine on the conjuntiva with a prophylactic antibiotic. Arch Ophthalmol. 1985;103(9):1340-2.

8. Starr MB. Prophylactic antibiotics for ophthalmic surgery. Surv Ophthalmol. 1983;27(6):353-73.

9. Ta CN, Egbert PR, Singh K, Shriver EM, Blumenkranz MS, Miño de Kaspar H. Prospective randomized comparison of 3-day versus 1-hour preoperative ofloxacin prophylaxis for cataract surgery. Ophthalmology. 2002; 109(11):2036-40; discussion 2040-1. Comment in: Ophthalmology. 2003; 110(12):2430-1; author reply 2431-2.

10. Snyder-Perlmutter LS, Katz HR, Melia M. Effect of topical ciprofloxacin $0.3 \%$ and ofloxacin $0.3 \%$ on the reduction of bacterial flora on the human conjuntiva. J Cataract Refract Surg. 2000;26(11):1620-5. Comment in: J Cataract Refract Surg. 2001;27(8):1144-6.

11. Ta CN, Chang RT, Singh K, Egbert PR, Shriver EM, Blumenkranz MS, et al. Antibiotic resistance patterns of ocular bacterial flora. A prospective study of patients undergoing anterior segment surgery. Ophthalmology. 2003; 110(10):1946-51

12. Höfling-Lima AL, Farah ME, Montenegro L, Alvarenga LS, Chalita MRC, You MCZ. Alterações da microbiota conjuntival e palpebral após uso tópico de lomefloxacina e tobramicina na cirurgia de catarata e cirurgia refrativa. Arq Bras Oftalmol. 2002;65(1):21-9.
13. Mather R, Karenchak LM, Romanowski EG, Kowalski RP. Fourth generation fluoroquinolones: new weapons in the arsenal of ophthalmic antibiotics. Am J Ophthalmol. 2002;133(4):463-6.

14. Hwang DG. Fluoroquinolone resistance in ophthalmology and the potential role for newer ophthalmic fluoroquinolones. Surv Ophthalmol. 2004; 49(Suppl 2):S79-83.

15. Sousa LB. Prevenção da infecção na cirurgia intra-ocular. In: Sousa LB, Freitas D, Höfling-Lima AL, Nishiwaki-Dantas MC, editores, Manual de prevenção da infecção nos procedimentos oftalmológicos. São Paulo: Lemos; 2003. p.129-34.

16. Moshirfar M, Feiz V, Vitale AT, Wegelin JA, Basavanthappa S, Wolsey DH. Endophthalmitis after uncomplicated cataract surgery with the use of fourthgeneration fluoroquinolones: a retrospective observational case series. Ophthalmology. 2007;114(4):686-91.

17. Deramo VA, Lai JC, Fastenberg DM, Udell IJ. Acute endophthalmitis in eyes treated prophylactically with gatifloxacin and moxifloxacin. Am J Ophthalmol. 2006;142(5):721-5.

18. Takahashi WY, Susanna Jr. R, Camargo ML, Yassuda N, Yanaguita RM, Silva LA, et al. Estudo da flora bacteriana em conjuntivas de olhos humanos. Rev Bras Oftalmol. 1975;34(2):53-60.

19. Arantes TE, Cavalcanti RF, Diniz MF, Severo MS, Lins Neto J, Castro $\mathrm{CM}$. Conjunctival bacterial flora and antibiotic resistance pattern in patients undergoing cataract surgery. Arq Bras Oftalmol 2006;69(1):33-6.

20. Garcia-Saénz MC, Peral Ortiz de la Torre MJ, De Castro Liébana M, Jiménez Martínez E, Garcia Sánchez JE, Freanadillo Sánchez MJ. Flora conjuntival según edades. Arch Soc Esp Oftalmol. 1999;74(7):379-84.

21. Recchia FM, Busbee BG, Pearlman RB, Carvalho-Recchia Cynthia, Ho AC. Changing trends in the microbiologic aspects of postcataract endophthalmitis. Arch Ophthalmol. 2005;123(3):341-6. 